\title{
Zika factores de riesgo en gestantes, malformaciones congénitas, diagnóstico
}

\section{Zika risk factors in pregnant women, congenital malformations, diagnosis}

Fatores de risco para zika em gestantes, malformações congênitas, diagnóstico

\author{
María J. Calle-Poveda I \\ majito callep@,hotmail.com \\ Lucia del Carmen Maza-Suarez II \\ lucymedic8@hotmail.com \\ Gulnara L. Fernandez-Bazurto III \\ gulnara-15.1@hotmail.com \\ María E. Villavicencio-Romero ${ }^{\mathrm{IV}}$ \\ mevr91@,hotmail.com
}

Recibido: 17 de mayo de 2019 * Corregido: 15 de junio de 2019* Aceptado: 05 de julio de 2019

\footnotetext{
Médica Cirujana, Universidad Laica Eloy Alfaro de Manabí, Manabí, Ecuador.

I. Médico, Universidad Laica Eloy Alfaro de Manabí, Manabí, Ecuador.

III. Médica Cirujana, Universidad Laica Eloy Alfaro de Manabí, Manabí, Ecuador.

Iv. Médico Cirujano, Universidad Laica Eloy Alfaro de Manabí, Manabí, Ecuador.
} 


\title{
Resumen
}

El Zika es un virus arbovirus trasmitido principalmente por la picadura de mosquito Aedes aegypti. Se transmite a través de la picadura del mosquito, de forma vertical (transmisión intrauterina o perinatal) y horizontal por contacto sexual, transfusiones sanguíneas o por exposición en el laboratorio. La relación entre la infección por el virus Zika y su posible repercusión fetal no había sido descrita con anterioridad, los crecientes casos de microcefalia (disminución importante del tamaño de la cabeza fetal con repercusión grave sobre el futuro desarrollo del cerebro) diagnosticados en Brasil durante el brote reciente de Zika, han desatado una alarma importante, Las técnicas de diagnóstico son muy específicas: técnicas de biología molecular (RT-PCR), únicamente disponibles en algunos laboratorios. Este virus puede estar relacionada a: problemas de crecimiento en la matriz, aborto espontáneo (cuando un bebé muere en la matriz antes de las 20 semanas de embarazo), nacimiento sin vida y síndrome congénito por el virus del Zika. El mecanismo por el cual el Zika causa alteraciones neurológicas fetales aún es desconocido, se plantean dos hipótesis: el Zika es un virus que por vía placentaria, accede directamente al cerebro y daña su desarrollo es decir, la ruta de entrada del virus podría ser a través de las glándulas secretoras uterinas. La segunda hipótesis hace referencia al efecto directo del Zika sobre la placenta. El diagnóstico definitivo requiere la confirmación por intermedio del laboratorio. Las muestras de plasma para realizar la RPC-TR, deberían ser tomadas en la fase inicial de la enfermedad, debido a que la viremia es de corta duración (entre 5 hasta 11 días). En la mujer gestante que se sospeche infección aguda por Zika, se debe solicitar RPC-TR, en la primera semana después del inicio de la enfermedad clínica y pruebas serológicas como IgM por ELISA de captura. En caso de encontrar alguna anormalidad ecográfica se debe realizar amniocentesis para realizar RPC-TR y confirmar el diagnóstico. La metodología usada es descriptiva, con un enfoque documental, es decir, revisar fuentes disponibles en la red, como google académico, con contenido oportuno y relevante desde el punto de vista científico que enriquezca el análisis del tema planteado en este artículo.

Palabras claves: Zika, microcefalia; malformaciones congénitas; técnicas de biología molecular (RT-PCR); placenta; infección.

\begin{abstract}
Zika is an arbovirus virus transmitted primarily by the Aedes aegypti mosquito bite. It is transmitted through the mosquito bite, vertically (intrauterine or perinatal transmission) and horizontally by sexual contact, blood transfusions or by exposure in the laboratory. The relationship between Zika virus infection and its possible fetal repercussion had not been previously described, the growing cases of microcephaly (a significant decrease in fetal head size with a serious impact on future brain development) diagnosed in Brazil during the Zika's recent outbreak has triggered an important alarm. Diagnostic techniques are very specific: molecular biology techniques (RT-PCR), only

\footnotetext{
María J. Calle-Poveda; Lucia del Carmen Maza-Suarez; Gulnara L. Fernandez-Bazurto; María E. Villavicencio-Romero.
}

680 Vol. 5, núm. 3, julio 2019, pp. 679-696
\end{abstract}


available in some laboratories. This virus may be related to: growth problems in the womb, spontaneous abortion (when a baby dies in the womb before 20 weeks of pregnancy), lifeless birth and congenital Zika virus syndrome. The mechanism by which Zika causes fetal neurological alterations is still unknown, two hypotheses are posed: Zika is a virus that, by placental route, directly accesses the brain and damages its development, that is, the route of entry of the virus could be through the uterine secretory glands. The second hypothesis refers to the direct effect of Zika on the placenta. The definitive diagnosis requires confirmation through the laboratory. Plasma samples to perform the RPC-TR, should be taken in the initial phase of the disease, because the viremia is short-lived (between 5 to 11 days). In pregnant women suspected of having acute Zika infection, RPC-TR should be requested in the first week after the onset of clinical illness and serological tests such as IgM by capture ELISA. If an ultrasound abnormality is found, amniocentesis should be performed to perform CPR-TR and confirm the diagnosis. The methodology used is descriptive, with a documentary approach, which is, reviewing sources available on the web, such as google scholar, with timely and scientifically relevant content that enriches the analysis of the topic raised in this article.

Key Word: Zika; microcephaly; congenital malformations; molecular biology techniques (RTPCR); placenta; infection.

\section{Resumo}

O zika é um vírus de arbovírus transmitido principalmente pela picada de mosquito Aedes aegypti. É transmitida através da picada do mosquito, verticalmente (transmissão intra-uterina ou perinatal) e horizontalmente por contato sexual, transfusões de sangue ou por exposição em laboratório. A relação entre a infecção pelo zika vírus e sua possível repercussão fetal não havia sido descrita anteriormente, os casos crescentes de microcefalia (uma diminuição significativa no tamanho da cabeça do feto com um sério impacto no desenvolvimento futuro do cérebro) diagnosticados no Brasil durante o $\mathrm{O}$ recente surto do Zika desencadeou um importante alarme As técnicas de diagnóstico são muito específicas: técnicas de biologia molecular (RT-PCR), disponíveis apenas em alguns laboratórios. Esse vírus pode estar relacionado a: problemas de crescimento no útero, aborto espontâneo (quando um bebê morre no útero antes de 20 semanas de gestação), nascimento sem vida e síndrome congênita do zika vírus. $\mathrm{O}$ mecanismo pelo qual o zika provoca alterações neurológicas fetais ainda é desconhecido, duas hipóteses são colocadas: o zika é um vírus que, por via placentária, acessa diretamente o cérebro e prejudica seu desenvolvimento, ou seja, a via de entrada do vírus pode ser através das glândulas secretoras uterinas. A segunda hipótese refere-se ao efeito direto do zika na placenta. O diagnóstico definitivo requer confirmação através do laboratório. Amostras de plasma para realizar o RPC-TR, devem ser tomadas na fase inicial da doença, pois a viremia é de curta duração (entre 5 e 11 dias). Em mulheres grávidas com suspeita de infecção aguda pelo Zika, o RPC-TR deve ser solicitado na primeira semana após o início da doença clínica e testes sorológicos, como o IgM, por ELISA de captura. Se uma anormalidade ultrassonográfica for 
encontrada, a amniocentese deve ser realizada para realizar a RCP-TR e confirmar o diagnóstico. A metodologia utilizada é descritiva, com uma abordagem documental, ou seja, revisando fontes disponíveis na web, como o google scholar, com conteúdo oportuno e cientificamente relevante que enriquece a análise do tema levantado neste artigo.

Palavras-chave: Zika, microcefalia; malformações congênitas; técnicas de biologia molecular (RTPCR); placenta; infecção

\section{Introducción.}

El virus Zika es un flavivirus que se transmite por la picada del mosquito Aedes aegypti que también es el vector que transmite el virus Dengue y el virus Chikungunya. El periodo de incubación se estima entre 2 y 14 días, produce un cuadro en general leve que incluye: fiebre, dolores musculares y articulares, lesiones cutáneas conjuntivitis y dolor de cabeza y que se resuelve entre 2 y 7 días. La mayoría de los casos de infección es asintomática.

La relación entre la infección por el virus Zika y su posible repercusión fetal no había sido descrita con anterioridad porque virus similares como el virus del dengue, no tenía efectos perjudiciales sobre el desarrollo fetal. En el año 2015 los abundantes casos de microcefalia diagnosticados en Brasil durante el brote de Zika han desatado una alarma importante, también en organismos sanitarios de varios países.

Por ser algo tan reciente, se desconoce la tasa de transmisión vertical (madre-hijo) del virus y el periodo de mayor riesgo, estudios en Brasil han encontrado que sea el primer trimestre del embarazo. Es importante si existe riesgo de haber contraído esta infección que la madre confirme los 
más pronto posible el diagnóstico porque el Zika durante el embarazo causa microcefalia y otros problemas graves del cerebro. La microcefalia ocurre cuando la cabeza del bebé es más pequeña de lo esperado, en comparación con bebés del mismo sexo y edad.

También este virus está relacionada a: problemas de crecimiento en la matriz, aborto espontáneo, nacimiento sin vida y síndrome congénito por el virus del Zika.

Esos defectos cambian la forma o función de una o más partes del cuerpo del recién nacido. Las mujeres embarazadas con infección del Zika durante el primer trimestre podrían tener más probabilidades de tener un bebé con defectos de nacimiento que las mujeres infectadas más tarde en el embarazo. Si su bebé nace con el síndrome congénito por el virus del Zika, necesitará atención de diferentes profesionales de la salud. De allí la importancia de informar y difundir toda información validada y seria que instruya a la población, especialmente a la expuesta a este virus con el propósito de contribuir a tratar lo más pronto posible y evitar complicaciones mayores, en el futuro. Este artículo abordará información relevante expuesta brevemente, a continuación.

\section{Metodología}

Esta investigación está dirigida al estudio del "Zika factores de riesgo en gestantes, malformaciones congénitas, diagnóstico". Para realizarlo se usó una metodología tipo descriptiva, con un enfoque documental, es decir, revisar fuentes disponibles en la red, como google académico, con contenido oportuno y relevante desde el punto de vista científico para dar respuesta a lo tratado en el presente artículo y que sirvan de inspiración para realizar otros proyectos. Las mismas pueden ser consultadas al final, en la bibliografía.

\section{Resultados}

683 Vol. 5, núm. 3, julio 2019, pp. 679-696 María J. Calle-Poveda; Lucia del Carmen Maza-Suarez; Gulnara L. Fernandez-Bazurto; María E. Villavicencio-Romero. 
El Zika es un virus arbovirus de la familia Flaviridae, genero Flavivirus que es trasmitido principalmente por la picadura de mosquito Aedes aegypti. El Zika, además de transmitirse a través de su vector (el mosquito) se puede transmitir de forma vertical (transmisión intrauterina o perinatal) u horizontal por contacto sexual, transfusiones sanguíneas o por exposición en el laboratorio.

La relación entre la infección por el virus Zika y su posible repercusión fetal no había sido descrita con anterioridad, se trataba como sucede con otros virus similares, como el virus del dengue, cuya infección no tenía efectos perjudiciales sobre el desarrollo fetal. Los crecientes casos de microcefalia (disminución importante del tamaño de la cabeza fetal con repercusión grave sobre el futuro desarrollo del cerebro) diagnosticados en Brasil durante el brote reciente de Zika, han desatado una alarma importante, también en organismos sanitarios internacionales. En la mayoría de casos no ha podido confirmarse la infección fetal porque las técnicas de diagnóstico son muy específicas: técnicas de biología molecular (RT-PCR), únicamente disponibles en algunos laboratorios de referencia (Goncé, 2018). Se desconoce la tasa de transmisión vertical (madre-hijo) del virus y el periodo de mayor riesgo, corresponde al primer trimestre del embarazo. Recientemente han sido publicados en la literatura científica, un par de casos con afectación cerebral grave fetal y con infección confirmada en líquido amniótico.

El síndrome congénito por el virus del Zika presenta las siguientes cinco características (Pearl, 2016):

- Microcefalia severa (el cráneo colapsa de forma parcial).

- Tejido cerebral disminuido con un patrón específico de daño cerebral.

- Daño (es decir, cicatrices, cambios en la pigmentación) en la parte posterior del ojo. 
- Articulaciones con limitaciones en el movimiento, como pie equino-varo.

- Demasiada tonicidad muscular que restringe el movimiento del cuerpo, apenas después del nacimiento.

Los bebés infectados con zika antes del nacimiento pueden presentar daños en los ojos y/o la parte del cerebro responsable de la visión, que compromete su desarrollo visual. Tanto los bebés con microcefalia como los que no la tienen pueden sufrir problemas oculares. Todo bebé nacido con infección congénita por el virus del Zika, debería recibir los exámenes y controles recomendados para detectar problemas oculares o de otro tipo, incluso si el bebé parece estar sano.

Un estudio en Brasil reveló que los bebés de 19 a 24 meses con infección congénita por el virus del Zika demostraron que tienen dificultades para sentarse, alimentarse y dormir solos. Los bebés también tuvieron convulsiones y problemas auditivos y oftalmológicos, como el hecho de no reaccionar ante el ruido del sonajero y no ser capaces de seguir a un objeto en movimiento con la mirada (Centro para el Diagnóstico y Control de Enfermedades. CDC, 2018). Cabe destacar que será necesario que los bebés afectados por el virus del Zika sigan recibiendo atención especializada por parte de diferentes proveedores de atención médica a medida que van creciendo.

No todos los bebés nacidos con infección congénita por el virus del Zika manifestarán todos estos problemas. Algunos bebés con Zika congénita que no tienen microcefalia en el nacimiento pueden experimentar un crecimiento tardío de la cabeza y desarrollar microcefalia posnatal posteriormente. Los investigadores están trabajando para determinar con cuánta frecuencia el Zika causa microcefalia si un bebé es expuesto en la matriz. Este virus puede estar relacionada a ( March of Dimes Foundation, 2019):

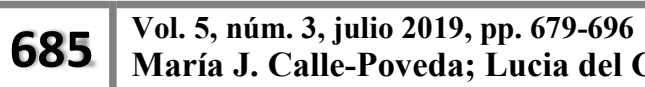
María J. Calle-Poveda; Lucia del Carmen Maza-Suarez; Gulnara L. Fernandez-Bazurto; María E. Villavicencio-Romero.
} 
- Problemas de crecimiento en la matriz.

- Aborto espontáneo. (cuando un bebé muere en la matriz antes de las 20 semanas de embarazo).

- Nacimiento sin vida.

- Síndrome congénito por el virus del Zika. Este es un grupo de cinco condiciones de salud que están presentes cuando el bebé nace y se asocian con la infección del Zika durante el embarazo. El síndrome incluye defectos de nacimiento (como la microcefalia) y otros problemas de salud y del desarrollo. El defecto de nacimiento es un problema de salud que está presente al nacer. Esos defectos cambian la forma o función de una o más partes del cuerpo. Pueden causar problemas en la salud en general, en cómo se desarrolla el cuerpo o cómo funciona.

El mecanismo por el cual el Zika causa alteraciones neurológicas fetales aún es desconocido. Actualmente se plantean dos hipótesis (Pivetta, Marzo 2017):

El Zika es un virus neurotrópico, que por vía placentaria, accede directamente al cerebro y daña su desarrollo. El virus debería estar presente en los estadios iniciales del desarrollo de la corteza cerebral, en fase temprana del neuro desarrollo, el embrión no tiene intercambio directo con la circulación materna, que empieza a fluir a partir de la semana 10 de gestación, es decir, la ruta de entrada del virus podría ser: a través de las glándulas secretoras uterinas; fuga del Zika por los tapones de trofoblasto; por el saco amniótico y saco vitelino o similar al virus del dengue, a través de exosomas placentarios, alcanzando el neuro epitelio del embrión o del feto. También, el virus puede transmitirse a través del semen, permitiendo otro acceso al embrión tempranamente. 
La segunda hipótesis hace referencia al efecto directo del Zika sobre la placenta. Algunos datos sugieren que la placenta sintetiza y secreta moléculas que son fundamentales para el desarrollo normal del cerebro, el Zika probablemente interrumpe la señal de síntesis molecular de proteínas, neuro péptidos, citosinas, en las capas externas de la placenta que podría causar o contribuir a la microcefalia.

Esta hipótesis estaría soportada por dos escenarios: el primero, donde la respuesta proinflamatoria de la placenta podría interrumpir el desarrollo del cerebro embrionario y el segundo sucede tempranamente, es la interrupción de las moléculas o vías específicas sintetizadas por la placenta, la que conlleva a una mutación de genes como los de la microcefalia (MCPH1-12, CEP63 y CASC5) sobre-expresándolos.

El por qué las células neuronales fetales son blanco para el virus, puede estar relacionado con la presencia de receptores que permiten la entrada del virus a la célula. Se ha encontrado que los receptores DC-SIGN, TAM (AXL y Tyro3) y en menor medida los TIM-1, median la entrada viral. Los receptores AXL se han encontrado expresado en células del endotelio vascular, macrófagos, astrocitos, células gliales y microglia durante el desarrollo de la corteza. La pérdida de su función por infecciones por flavi virus produce una disminución de la integridad de la barrera en su capa basal y pérdida de la unión de células endoteliales de la microvasculatura cerebral, permitiendo la entrada del virus al cerebro. El AXL es conocido por mediar la entrada del Zika y dengue a las células de la piel humana. También muestra una alta expresión en las células de la gliaradial, comparado con la expresión de los otros receptores (TYRO3 y DC-SIGN). La microcefalia se explica como el resultado de una depleción de la población de la glía radial y de las células madres neurales en el cerebro en desarrollo, ya sea por muerte celular o por diferenciación prematura.

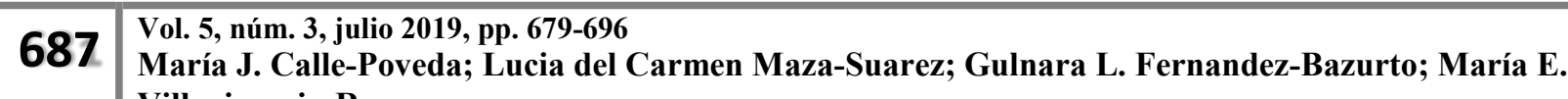
Villavicencio-Romero.
} 
Las lesiones oculares asociadas con microcefalia pueden ser explicadas por la expresión del receptor AXL en las células que tienen una firma genética de células madres como las células de la zona marginal ciliar adyacente a la retina neural. Con el seguimiento de los nuevos casos e investigaciones, se descubrió que la infección por el Zika no sólo se asocia a microcefalia, sino también a anormalidades cerebrales graves convirtiéndose en el llamado síndrome de Zika congénito. Si la infección ocurre entre el primer y el final del segundo trimestre, puede desencadenar alteraciones en el proceso de formación fetal; el período más crítico para la presencia de microcefalia, es el primer trimestre. La tabla número 1 resume estos resultados:

Tabla $\mathbf{N}^{\circ} 1$. Hallazgos clínicos e imágenes usadas para el síndrome de Zika congénito.

\begin{tabular}{|c|c|c|}
\hline Examen Físico & Oculares & Imágenes \\
\hline $\begin{array}{l}\text { Perímetro cefálico anormal. } \\
\text { Hipertonia o espasticidad, hiper } \\
\text { reflexia. } \\
\text { Cutis girata. } \\
\text { Irritabilidad. } \\
\text { Tremor y/o convulsiones. } \\
\text { Malformaciones de pie. } \\
\text { Bajo peso para la edad } \\
\text { gestacional. } \\
\text { Artrogriposis. } \\
\text { Restricción del crecimiento } \\
\text { intrauterino. }\end{array}$ & $\begin{array}{l}\text { Pigmento moteado focal. } \\
\text { Atrofia macular. } \\
\text { Anomalías del nervio óptico. } \\
\text { Perdida del reflejo foveal. } \\
\text { Atrofia coriorretiniana. } \\
\text { Subluxación de lentes. }\end{array}$ & $\begin{array}{l}\text { Calcificaciones intra cerebrales. } \\
\text { Alteración de la migración } \\
\text { neuronal. } \\
\text { Dilatación ventricular. } \\
\text { Ausencia de cuerpo calloso. } \\
\text { Hidranencefalia. } \\
\text { Atrofia cortical y/o subcortical. }\end{array}$ \\
\hline
\end{tabular}

Fuente: (Alvarado, Junio 2016)

Si la infección por el Zika ocurre en los meses finales del embarazo, puede manifestar retardo mental, sordera neuro sensorial y/o lesiones oftalmológicas, incluso enfermedades fetales o 
desenlaces fatales en la mujer embarazada. Durante el período gestacional la ultrasonografía entre la semana 14-20 puede no mostrar anormalidades y solamente hacia la semana 29 puede ser evidenciada la microcefalia.

Los fetos de madres que han adquirido Zika durante el embarazo, se deben evaluar con neuro imágenes, ya sea ultrasonografía transfontanelar o tomografía computarizada cerebral o resonancia magnética cerebral. El Virus ha presentado transmisión durante el parto, adicionalmente ha sido encontrado en la lactancia materna mediante RPC-TR; mientras que no se han encontrado partículas en fase repetitiva, amerita vigilancia de esta probable vía.

\section{Diagnóstico}

Debido a que no hay un factor clínico, bioquímico o radiológico patognomónico de la infección por Zika, el diagnóstico definitivo requiere la confirmación por intermedio del laboratorio. El estándar de oro de la infección por Zika es el aislamiento del virus en un cultivo. Como desventajas muestra: baja sensibilidad, el tiempo requerido para el crecimiento del virus (alrededor de 10 días) y la carga viral del espécimen.

Un diagnóstico rápido de la infección por el Zika es por intermedio de la RPC-TR. Las muestras de plasma para realizar la RPC-TR, deberían ser tomadas en la fase inicial de la enfermedad, debido a que la viremia es de corta duración (entre 5 hasta 11 días). Se ha detectado presencia del ARN del virus por RPC-TR en el plasma de una mujer embarazada entre las 4 y 10 semanas después del inicio clínico de la infección. Estos hallazgos hacen considerar al embarazo como condición favorable a la infección del Zika. Existen limitaciones con respecto a esta prueba, debido a la falta de controles y muestras para estudios de validación (Moraes, Diciembre 2016). 
En la mujer gestante en que se sospeche infección aguda por Zika, se debe solicitar RPC-TR, en la primera semana después del inicio de la enfermedad clínica y pruebas serológicas como IgM por ELISA de captura. Las pruebas serológicas tienen alta reacción cruzada con otros flavivirus, por lo cual, se debe hacer una buena interpretación de un resultado IgM positivo, en el contexto de una zona endémica de dengue y Zika. En caso de ser positiva algunas de estas pruebas, se debe realizar RPC-TR en el líquido amniótico, así como ultrasonografía de detalle anatómico. De resultar negativas y la primera ultrasonografía sea normal, se debe realizar seguimiento estrecho clínico y ultrasonográfico, en alta sospecha de infección por Zika en una zona endémica. En el caso de encontrar alguna anormalidad ecográfica se debe realizar amniocentesis para realizar RPC-TR y confirmar el diagnóstico.

En el caso de la mujer gestante asintomática que viaje a una zona endémica de Zika, se recomienda efectuar RPC-TR en plasma y orina dentro de las dos semanas después de la exposición. Para el caso de la gestante que viva en la zona endémica, se sugiere la realización de IgM como parte del programa de control prenatal en los dos primeros trimestres; si el resultado es positivo, se sugiere la realización de RPC-TR. Si la IgM resulta positiva, ambigua o no concluyente, debe ser confirmada mediante la prueba de neutralización por reducción en placa (Coronell, diciembre 2016).

\section{Zika en cifras por Latinoamérica}

La Organización Mundial de la Salud (OMS) estima que 276000 recién nacidos mueren cada año debido a anomalías congénitas y los niños que logran superar esta etapa sufren diferentes discapacidades y afectación en su calidad de vida con impacto en su núcleo familiar, instituciones, sistemas de salud y la sociedad. Son pocas las alternativas con efectividad comprobada para la prevención de anomalías congénitas. Entre ellas están la vacunación, la ingesta de ácido fólico y el

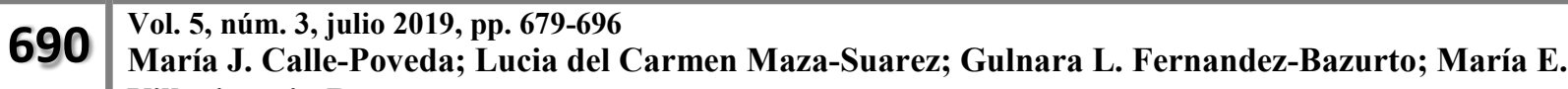
Villavicencio-Romero.
} 
enriquecimiento de alimentos básicos o el suministro de complementos, así como los cuidados prenatales adecuados (Mendivelso, mayo 2019).

En 2015, el mundo se vio afectado por un brote de infección por virus del Zika (ZIKV, por sus siglas en inglés), comenzó en las islas del Pacífico sur y se propagó un brote en Brasil con una incidencia entre 500 mil a 1 millón 400 mil casos. El comportamiento clínico de la enfermedad es síndrome febril agudo. La mayor preocupación es la confirmación de su efecto neurotrópico y la relación causal directa con microcefalia en recién nacidos de las zonas con una mayor incidencia por el brote en Brasil. El Zika se extendió rápidamente a Surinam, Guatemala, Panamá, Méjico, Colombia, Venezuela, Paraguay, Argentina. En Abril de 2016 se informó el primer caso de Zika importado en Uruguay. Se están realizando múltiples estudios clínicos en ciencias básicas y otras áreas para generar más evidencia. Esto no solo ayudará a entender los mecanismos de afectación neurológica, sino la aparición de otros trastornos neurológicos relacionados.

El análisis de brotes o emergencias en salud pública para enfermedades crónicas no trasmisibles (ENT) es infrecuente y presenta variaciones metodológicas radicales si se compara con el estudio de situación de brotes en enfermedades infecciosas. Las razones obedecen porque los desenlaces en salud y el efecto de intervenciones para su control presentan una dinámica diferente y de resultados observable en el muy largo plazo.

La llegada del Zika a Colombia, se presenta como una epidemia en casi todo el territorio nacional, se ubica como el segundo país de América con 47.771 casos de Zika superado por Brasil. Se han documentado infecciones en 35 de las 37 entidades territoriales mayores (departamentos y distritos), comprometiendo a toda la población, siendo muy vulnerables las mujeres embarazadas. En relación a las gestantes, del total de casos notificados, $18,61 \%$ (8.890), siendo 812 casos

\footnotetext{
691 Vol. 5, núm. 3, julio 2019, pp. 679-696 María J. Calle-Poveda; Lucia del Carmen Maza-Suarez; Gulnara L. Fernandez-Bazurto; María E. Villavicencio-Romero.
} 
confirmados por laboratorio, 7.131 confirmados por clínica y 947 casos sospechosos (Alvarado, Junio 2016). Considerando los riesgos potenciales para este grupo, el Ministerio de Salud y Protección Social determinó que las mujeres gestantes son un grupo de alto riesgo. Sin embargo, los resultados de confirmación diagnóstica son un poco desalentadores: $9.1 \%$ de las gestantes con cuadro clínico con riesgo de infección se confirman mediante RT-PCR, cifra muy baja de casos confirmados ante la oportunidad de poder confrontar el impacto perinatal de esta infección. Por otro lado, no se tienen en Colombia pruebas serológicas para Zika, que permitan la confirmación diagnóstica a un mayor grupo poblacional. Las pruebas usadas para diagnóstico pueden tener reacción cruzada con otros virus, como el dengue, lo que conllevaría a errores diagnósticos.

Otro elemento que dificulta su diagnóstico: un porcentaje de infecciones de Zika podrían ser asintomáticas y auto limitadas, hasta en un $80 \%$. En consecuencia, se desconoce el real impacto que tiene la infección en la población colombiana. Potencialmente puede existir un número de mujeres gestantes infectadas asintomáticas, con riesgo potencial de daño fetal. Al parecer el riesgo es mayor, si la exposición ocurre entre semana las semanas 14 y 17 de gestación.

El Ministerio de Salud de Brasil ha dicho que la cantidad de casos presuntos de microcefalia aumentó a 3.893 hasta el 16 de enero de 2016 frente a los 3.530 registrados diez días antes.

El número de muertes registradas de bebés con malformaciones subió a 49, según han confirmado funcionarios del Ministerio en una rueda de prensa. Hasta la fecha, las autoridades sanitarias han confirmado sólo seis casos de microcefalia en los que los niños estaban infectados con el virus zika, que es transmitido por mosquitos (Levante el Mercantil Valenciano, 2016). 
El aumento de los casos desde que el año pasado se detectase el nuevo virus en Brasil llevó al Ministerio a relacionarlo con las malformaciones congénitas y a advertir a las mujeres embarazadas de que utilicen repelente de insectos para evitar las picaduras de mosquitos. Investigadores brasileños dieron nuevos pasos para demostrar que el Zika provoca microcefalia. El centro biomédico Fiocruz en Curitiba anunció el hallazgo del virus en la placenta de una mujer que tuvo un aborto espontáneo, demostrando que el zika puede llegar al feto (Coronell, Diciembre 2016).

En Ecuador se registraron 5.347 casos de zika desde el 2016 hasta el 7 de marzo de 2018, según el Ministerio de Salud Pública (MSP). El 60\% de los diagnosticados en 2017 tenían entre 20 y 49 años. El 82,6\% de ellos fueron mujeres, de ellas se sometieron a la prueba en el sistema público para determinar si están embarazadas y/o presentan los síntomas. Desde 2016 se han registrado 965 embarazadas con Zika. El 2\% de ellas tuvieron bebés con el síndrome congénito asociado al virus, 21 nacidos en las provincias de Guayas (8), Manabí (5), Pichincha (2), Los Ríos (2), El Oro (2), Sucumbíos (1) y Santo Domingo de los Tsáchilas (1). Según cifras oficiales: con microcefalia en veinte de los casos y uno con labio fisurado.

Adicionalmente, 17 bebés dieron positivo a zika, pero no han presentado malformación congénita y se identificaron cinco casos no concluyentes que se encuentran en proceso de investigación (Herrera, 2018).

\section{Conclusión}

Las infecciones congénitas son importantes de evaluar durante el periodo prenatal y perinatal debido a posibles resultados adversos, principalmente de tipo neurológico. El aumento de forma

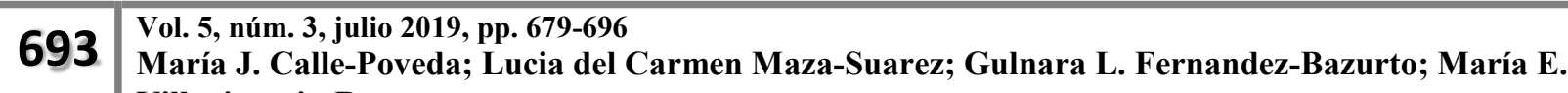
Villavicencio-Romero.
} 
progresiva por la aparición de otras infecciones que muestran repercusión importante en el periodo neonatal. Estos últimos son responsables de pandemias en los últimos años como el ébola, hepatitis $\mathrm{C}$, dengue, chikungunya y recientemente Zika, muchas de estas infecciones con repercusión perinatal, asociado a infecciones trasmitidas por vectores se hacen relevantes por sus secuelas.

Su infección está relacionada con resultados adversos durante la gestación, como anomalías fetales, parto pre término, muerte fetal y bajo peso. La transmisión vertical tiene expresiones clínicas variables, con riesgo incrementado de desarrollar cuadros severos como hemorragia cerebral, compromiso severo neonatal e incluso la muerte. La infección fetal ocasionada por el Zika observada durante 2015-2016 en varios países latinoamericanos abrió varias líneas de investigación para contrarrestar efectos adversos como el crecimiento significativo del número de neonatos con microcefalias. El diagnóstico y abordaje depende del momento de confirmación de este virus durante el embarazo.

Si la infección ocurre entre el primer y el final del segundo trimestre, puede desencadenar alteraciones del proceso de formación fetal; el período más crítico para la presencia de microcefalia, es el primer trimestre. Además de malformaciones se evidencia restricción del crecimiento intrauterino, muerte fetal o imágenes anormales en ultrasonografía. Si la infección por el Zika ocurre en los estadios finales del embarazo, puede tener una presentación diferente como retardo mental, sordera neuro sensorial y/o lesiones oftalmológicas, incluso enfermedades fetales o desenlaces fatales en la mujer embarazada.

Durante el período gestacional la ultrasonografía entre la semana 14 a la 20 puede no mostrar anormalidades, solamente hacia la semana 29 puede ser evidenciada la microcefalia. Los fetos de madres que han adquirido Zika durante el embarazo, se deben evaluar con neuro imágenes, ya sea

\footnotetext{
694 Vol. 5, núm. 3, julio 2019, pp. 679-696 María J. Calle-Poveda; Lucia del Carmen Maza-Suarez; Gulnara L. Fernandez-Bazurto; María E. Villavicencio-Romero.
} 
ultrasonografía o tomografía computarizada o resonancia magnética cerebral. No existe vacuna contra este virus hasta el momento, las medidas de prevención tanto generales y específicas son la vía más expedita para evitar la propagación de este virus.

Reconocer que el Zika es la causa de ciertos defectos congénitos no significa que todas las mujeres embarazadas infectadas con el virus del Zika tendrán un bebé con un defecto de nacimiento. Significa que la infección por el virus del Zika durante el embarazo aumenta la probabilidad de tener estos problemas. Los científicos siguen estudiando la manera en que el virus del Zika afecta a las madres y a sus hijos con el objetivo de entender mejor la gama completa de posibles problemas de salud que pueden aparecer durante el embarazo a raíz de la infección por el virus del Zika.

\section{Bibliografía}

Alvarado, J. (Junio 2016). Zika en neonatos: Todo no está dicho. Revista de la Universidad Industrial de Santander. Salud, Volumen 48 número 2., Recuperado por http: www.scielo.conicyt.cl.

Centro para el Diagnóstico y Control de Enfermedades. CDC. (Marzo de 2018). Microcefalia y otros defectos congénitos. Obtenido de Centro Nacional de Enfermedades Infecciosas Zoonóticas y Emergentes (NCEZID): www.cdc.gov.

Coronell, W. (Diciembre 2016). Infección por virus del Zika en el embarazo, impacto fetal y neonatal. Revista chilena de infectología. Vol. $33 \mathrm{~N}^{\circ} .6$, Recuperado por http: www.scieloanalytics.cl.

Goncé, A. (Julio de 2018). El virus Zika: posibles efectos sobre el embarazo y recomendaciones. Obtenido de INATAL: www.inatal.org.

Herrera, G. (7 de Marzo de 2018). El Universo. Obtenido de 21 bebés con mal congénito asociado al zika en Ecuador: www.eluniverso.com.

Levante el Mercantil Valenciano. (21 de Enero de 2016). Aumentan las malformaciones congénitas por el virus zika en Brasil. Transmitido por mosquitos, provoca un desorden por el que los bebés nacen con cerebros más pequeños., Recuperado por http: www.levante.emv.com.

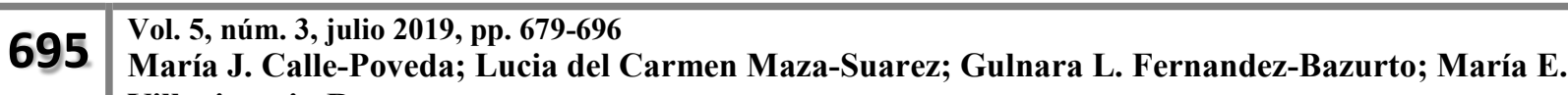
Villavicencio-Romero.
} 
March of Dimes Foundation. (23 de Mayo de 2019). El virus del Zika y el embarazo. Obtenido de NACERSANO: www.nacersano.marchofdimes.org.

Mendivelso, F. (Mayo 2019). Notificación de defectos congénitos por brote del virus del Zika en Colombia, 2015-2017. Revista Panamericana de Salud Pública, pág. 38 - 43. www.ncbi.nlm.nih.gov.

Moraes, M. (Diciembre 2016). Infección por virus Zika en el embarazo y el recién nacido. Archivos de Pediatría del Uruguay, Vol. $87 \mathrm{~N}^{\circ} 4$, www.scielo.analytics.uy.

Pearl, E. (Octibre de 2016). 5 cosas que debe saber sobre el Zika y el embarazo. Obtenido de Kids Health para Padres.: www.kidshealth.org.

Pivetta, M. (Marzo 2017). El zika al comienzo del embarazo. Pesquisa fapesp, edición 253, www.revistapesquisa.fapesp.br. 